\title{
Characterization of Cod (Gadus morhua) frame composition and its valorization by enzymatic hydrolysis
}

Jafarpourkhozaghi, Ali; Gomes, Rocio Marciel; Gregersen, Simon; Sloth, Jens Jørgen; Jacobsen, Charlotte; Sørensen, Ann-Dorit Moltke

Published in:

Journal of Food Composition and Analysis

Link to article, DOI:

10.1016/j.jfca.2020.103469

Publication date:

2020

Document Version

Peer reviewed version

Link back to DTU Orbit

Citation (APA):

Jafarpourkhozaghi, A., Gomes, R. M., Gregersen, S., Sloth, J. J., Jacobsen, C., \& Sørensen, A-D. M. (2020).

Characterization of Cod (Gadus morhua) frame composition and its valorization by enzymatic hydrolysis. Journal of Food Composition and Analysis, 89, [103469]. https://doi.org/10.1016/j.jfca.2020.103469

\section{General rights}

Copyright and moral rights for the publications made accessible in the public portal are retained by the authors and/or other copyright owners and it is a condition of accessing publications that users recognise and abide by the legal requirements associated with these rights.

- Users may download and print one copy of any publication from the public portal for the purpose of private study or research.

- You may not further distribute the material or use it for any profit-making activity or commercial gain

- You may freely distribute the URL identifying the publication in the public portal 


\section{Characterization of Cod (Gadus morhua) frame composition and its valorization by enzymatic hydrolysis}

3 Ali Jafarpour ${ }^{1,2}$, Rocio Marciel Gomes ${ }^{1}$, Simon Gregersen ${ }^{3}$, Jens Jørgen Sloth ${ }^{4}$, Charlotte Jacobsen ${ }^{1}$, AnnDorit Moltke Sørensen ${ }^{1}$

$5{ }^{1}$ Research group for Bioactives - Analysis and Application, Division of Food Technology, National Food Institute, Technical University of Denmark, Denmark ${ }^{3}$ Department of Chemistry and Bioscience, Aalborg University, Denmark

${ }^{4}$ Research group for Nano-Bio Science, Division of Food Technology, National Food Institute, Technical University

\section{Abstract}

13 This study aimed at evaluating proximate composition, phosphorous content, amino acid (AA) and 14 fatty acid (FA) profiles of cod (Gadus morhua) frame at five different sampling times (March 2017 15 to March 2018). Furthermore, the valorization possibility of cod frame by application of enzymatic 16 hydrolysis was investigated using the samples from September 2017. In terms of protein content, 17 this sample showed a significantly $(\mathrm{P}<0.05)$ higher level $(16.5 \%)$ compared to the other samples, 18 whereas lipid and phosphorous contents varied in a narrow range of $0.9-1.1 \%$ and $2.9-4.4 \%$, 19 respectively, $(\mathrm{P}<0.05)$. Furthermore, the total amino acids (AAs) content varied from about 98 to $20155 \mathrm{mg} / \mathrm{g}$ in minced cod frame. Enzymatic hydrolysis of minced cod frame (MCF) and heated cod 21 meat (HCM) was carried out by application of Alcalase and Neutrase, either individually or 22 sequentially to obtain fish protein hydrolysate $(\mathrm{FPH})$ and bone powder rich in phosphorus and 23 calcium. The protein content of $\mathrm{FPH}$ varied from $76 \%$ to $84 \%$ and soluble-nitrogen in 
24 trichloroacetic acid (SN-TCA) index varied from 30.6-40.3\%, resulting in similar trends for yield

25 and nitrogen recovery. Considerable amounts of phosphorus and calcium (330 and $583 \mathrm{~g} / \mathrm{kg}$,

26 respectively) were recovered from the cod frame bones after enzymatic hydrolysis. This study

27 showed that it is possible to produce bone powder rich in phosphorous and calcium as well as

28 peptides from the cod frame. Thus, the cod frame side-stream can be converted from its current

29 use as mink feed ingredient into higher value products for human consumption, without generating

30 new waste products.

31 Keywords: cod frame composition, amino acid profile, free fatty acid, fish protein hydrolysate,

32 minerals

\section{Introduction}

35 Globally, the direct share of human consumption and non-food products (mainly fish meal and 36 fish oil) from marine catches and aquaculture productions is reported to be 151 and 20 million 37 tonnes, respectively, in 2016 (FAO, 2018). More than $60 \%$ of the aquatic biomass end up as by38 products, including the head, skin, trimmings, fins, frames, viscera and roe from seafood 39 processing factories (Chalamaiah et al., 2012). Hence, there is a great potential for taking 40 advantage of these apparent waste or low value materials, by turning them into actual authentic 41 value added components such as lipids, chitin and chitosan, calcium, nucleic acids, pigments, and 42 biologically active peptides. In cod fillet production, as much as $60 \%$ of the whole fish is by43 products, the backbone yielding about $15 \%$ of the fish weight (Gildberg, 1993). Fish backbone is 44 rich in minerals such as calcium and phosphorous (Toppe et al., 2007) and contains residual fish 45 meat that was not removed during the filleting process. 
46 Despite general awareness of health benefits of elements such as calcium and phosphorus, most

47 societies still suffer from deficiencies in their diets (Soetan et al., 2010). Calcium deficiency is

48 associated with osteoporosis, which affects 26 million lives annually (Melton, 1995). Dairy

49 products are considered the major source of calcium. However, due to some consumption

50 inhibitory factors like lactose intolerance, saturated fat and cholesterol alternative sources of

51 calcium such as marine by-products have attracted serious attention. Recently, apart from protein

52 isolation and peptide recovery, the utilization of organic components or minerals from the fish

53 bone have been reported (Kim and Jung, 2006; Nemati et al., 2017; Terzioğlu et al., 2018). The

54 most commonly reported recovery method of calcium and phosphorus from the fish backbone is

55 boiling of fish frame with subsequent grinding to obtain a bone powder (Toppe et al., 2007).

56 However, in other studies, alkaline solubilization has been combined with boiling as an efficient

57 approach for fish bone powder recovery (Nemati et al., 2017).

58 In terms of protein/peptide recovery, application of enzymatic hydrolysis is considered as an

59 environmental friendly treatment to produce a large and diversified range of products from fish

60 side-streams compared to less efficient mechanical and chemical methods. Enzymes are highly

61 versatile biocatalysts that have evolved to function under optimized conditions for the host

62 organism. Consequently, different enzymes have different activity profiles spanning broad activity

63 ranges, highly specific ranges, and even extreme ranges in terms of e.g. temperature and $\mathrm{pH}$

64 (Robinson, 2015). Therefore, application of enzymatic hydrolysis in the food industry is

65 increasing, as it is possible to find enzymes with high proteolytic activity under the applied

66 processing conditions (Oliveira et al., 2015). Protein rich fish by-products have been subject to

67 different proteases for digestion of intact proteins and liberating potential bioactive peptides in the

68 form of fish protein hydrolysate (FPH) (Guérard and Shahidi, 2007). While some proteases show 
69 unselective specificity towards cleaving of peptide bond in a variety of substrates, others show

70 high specificity for particular sequences, which influence the functional properties of generated

71 peptides in different food systems. However, protease specificity is one side of the story; another

72 side is the variation in substrate characteristics and its quality due to different variables such as

73 species, sex, seasonal variation and catchment region. Apparently, physiochemical properties of

74 fish muscle can be influenced by seasonal variation, which can subsequently affect its processing

75 and functional properties (Ingolfsdottir et al., 1998). However, information on influence of

76 different catchment periods on nutritional quality parameters such as amino acids, fatty acids

77 profile and mineral content of cod frame is not available. Such information will give a better

78 knowledge of the potential of using cod frame as an underutilized side-stream for various food

79 applications. Furthermore, heat treatment to facilitate the separation of the meat remaining on the

80 backbone could be an obstacle in recovery of functional proteins, due to protein denaturation.

81 Therefore, enzymatic hydrolysis could be a practical approach for recovery of functional FPH after

82 application of heat treatment on fish backbone. Thus, it would be necessary to evaluate the impact

83 of heating of fish backbone on efficiency of enzymatic recovery and functionality of obtained FPH,

84 as it has not been studied to any detail, previously.

85 The current study was performed to increase the knowledge of possible variation in nutritional

86 composition of cod (Gadus morhua) frame from different catchment periods. The second aim was

87 to examine a practical short-term hydrolysis process on cod frame using two commercial proteases,

88 Alcalase (Alc) and Neutrase (Neut), either individually or sequentially, and to evaluate their

89 efficiency in producing FPH powder and bone powder, rich in phosphor and calcium. Moreover,

90 since the rigid structure of the cod frame was a major obstacle in the grinding process, this study

91 also aimed at investigating whether heating of fish frames, for facilitating the meat separation 
92 process, could affect the extraction efficiency and functionality of recovered FPH powder and the

93 resulting calcium and phosphorus content in the bone powder.

\section{Materials and Methods}

96 Cod frames were received from Espersen A/S, (Klaipeda city-Lithuania) in batches of $7 \mathrm{~kg}$ at five

97 different sampling times (March 2017, June 2017, September 2017, December 2017 and March

98 2018). The captured cods were processed (filleted) on-site and the frames (side-stream) were

99 packed, transported to the National Food Institute (Kgs. Lyngby, Denmark) in frozen condition,

100 and stored at $-40^{\circ} \mathrm{C}$ upon arrival. Alcalase ${ }^{\circledR} 2.4 \mathrm{~L} \mathrm{FG}$ (Alc; declared activity of $2.4 \mathrm{AU} / \mathrm{g}$ ) and

101 Neutrase $^{\circledR} 0.8 \mathrm{~L}$ (Neut; declared activity $0.8 \mathrm{AU} / \mathrm{g}$ ), both as endopeptidase with broad specificity

102 and high activity in range of $\mathrm{pH}$ and temperature, were provided by Novozymes (Bagsværd,

103 Denmark). All chemical reagents used for experiments were of analytical grade.

104

105 Preparation of cod frames for characterization

106 For each sampling point, the $7 \mathrm{~kg}$ block was thawed overnight in the fridge prior to the analysis.

107 The frames were separated and one frame was selected and cut into smaller pieces. Three samples

108 were made out of one frame. The small pieces were grinded into a homogenous mass using liquid 109 nitrogen. The samples were stored at $-40{ }^{\circ} \mathrm{C}$ until further analysis

110

111 Dry matter

112 Homogenized thawed cod frame sample (approx. $2 \mathrm{~g}$ ) were dried for 20-24 $\mathrm{h}$ in an oven at 102-

$113105^{\circ} \mathrm{C}$. All analyses were carried out in triplicate samples $(\mathrm{n}=3)$. The dry matter [\%] was calculated 114 based on weight of wet and dry sample. 


\section{Lipid extraction and determination of oil content}

117 The lipid content of cod frames was measured gravimetrically according to Bligh and Dyer method

118 with reduced amount of solvent (Bligh and Dyer, 1959; Iverson et al., 2001). For the extraction,

119 chloroform:methanol $(1: 1, \mathrm{v} / \mathrm{v})$ was used by fixing the centrifuge tube containing $30 \mathrm{~mL}$ methanol

120 to its holder on the Ultra Turrax. Then $15 \mathrm{ml}$ chloroform were added and mixed for 30 seconds

121 with a speed of $15000 \mathrm{rpm}$. Subsequently, another $15 \mathrm{ml}$ chloroform were added and the solution

122 was mixed again for 30 seconds, followed by centrifugation at $1665 \times \mathrm{g}$ and $18{ }^{\circ} \mathrm{C}$ for 10 minutes.

123 After centrifugation, the methanol:water phase (upper phase) was removed and extract

124 (chloroform phase) was filtered down into a $50 \mathrm{ml}$ Pyrex bottle. Extracts $(10 \mathrm{~g})$ were left overnight

125 at room temperature, dried (oven 1-2 h, $105^{\circ} \mathrm{C}$ ) and weighed. All analyses were carried out in 126 triplicate samples (with two analytical replicates; $n=3 \times 2$ ).

128 Fatty acid composition

129 The lipid extract was used to determine the fatty acid composition. Lipid extract was evaporated 130 to dryness under nitrogen and re-dissolved in internal standard (100 $\mu \mathrm{L}, \mathrm{C} 23: 0$ in heptane), 200

$131 \mu \mathrm{L}$ heptane with BHT and $100 \mu \mathrm{L}$ toluene. Boron trifluoride reagent $(20 \%)$ was added for lipid 132 transesterification in a one-step procedure using a microwave (Multiwave 3000 SOLV, Rotor: 133 64MG5, Anton Paar, Graz, Austria). Samples were heated for $5 \mathrm{~min}$ at $500 \mathrm{~W}$ and cooled down 134 for $10 \mathrm{~min}$. Then samples were mixed with $1 \mathrm{~mL}$ saturated $\mathrm{NaCl}$ solution and $0.7 \mathrm{~mL}$ heptane. The 135 top layer was used for fatty acid composition analysis by gas chromatography with flame 136 ionization detection (GC-FID; Column: DB-wax column $(10 \mathrm{~m} \times \mathrm{ID} 0.1 \mathrm{~mm} \times 0.1 \mu \mathrm{m}$ film 137 thickness, J\&W Scientific, Folsom, CA)) according to AOCS official Method Ce 1b-89. Results 
138 were reported as percentages of total fatty acids. All analyses were carried out in triplicate samples

139 (with two analytical replicate; $n=3 \times 2$ ).

\section{Protein content}

142 The protein content was measured based on total nitrogen content analyzed by Dumas (Rapid

143 MAX N exceed cube N/protein analyzer, Elementar Analysensysteme GmbH, Germany).

144 Depending on the sample type, $250 \mathrm{mg}-500 \mathrm{mg}$ of sample was used for the determination. Crude

145 protein was estimated in all samples by multiplying the total nitrogen content (\%) by a factor of

146 6.25. All analyses were carried out in triplicate samples (with two analytical replicates; $n=3 \times 2$ ).

\section{Amino acid composition}

149 The amino acid composition was determined by HPLC-MS, following hydrolysis and 150 derivatization using EZ:faast amino acid kit (Phenomenex, Torrance, CA, USA) (Ghelichi et al., 151 2017). The acid hydrolysis was applied in order to release the amino acid using $6 \mathrm{M} \mathrm{HCl}$ at 110

$152{ }^{\circ} \mathrm{C}$ for $18 \mathrm{~h}$ in oven. The subsequent neutralized samples were purified by a solid-phase extraction 153 sorbent tip and derivatization was performed following the injection of sample aliquots into an 154 Agilent HPLC 1100 instrument (Santa Clara, CA, USA) coupled to an Agilent ion trap mass 155 spectrometer. The amino acids were identified by comparing retention time and mass spectra of 156 an external standard mixture. Calibration curves were prepared and analyzed by HPLC-MS for 157 quantification. All analyses were carried out in triplicate samples (with two analytical replicate; $158 n=3 \times 2)$.

160 Phosphorous content measured by spectrophotometry 
161 Before measuring the phosphorous content in the cod frames, the samples were burnt in an oven

$162\left(30 \mathrm{~min}\right.$ at $200{ }^{\circ} \mathrm{C}, 30 \mathrm{~min}$ at $300{ }^{\circ} \mathrm{C}, 1 \mathrm{~h}$ at $400{ }^{\circ} \mathrm{C}$ and $12 \mathrm{~h}$ at $\left.600{ }^{\circ} \mathrm{C}\right)$ and the ashes were used for

163 determination of phosphorous. Ash samples were weighed and sulfuric acid (5.6 M) and

164 ammonium molybdate (2.5\%) were added for reaction. Under acidic conditions, phosphate is 165 converted to phosphomolybdic acid. Under reduction (stannous chloride, 2.5\%) a blue colored 166 complex was formed. The intensity of the complex was measured spectrophotometrically at 690 $167 \mathrm{~nm}$ after 15-25 min and quantified using a standard curve prepared from a phosphate standard 168 solution (Sodium dihydrogen phosphate dodecahydrate, $1.05 \mathrm{mM}$ containing $0.1 \mathrm{mg} \mathrm{PO}_{4}^{3-} / \mathrm{mL}^{2}$ $1690.033 \mathrm{mg} \mathrm{P} / \mathrm{mL}$ ). All analyses were carried out in triplicate samples (with two analytical replicates; $170 \mathrm{n}=3 \times 2)$.

171

\section{Preparation of cod frame hydrolysates}

173 Following Liaset et al. (2000), proteolysis variables such as temperature, $\mathrm{pH}, \mathrm{E} / \mathrm{S}$ ratio and time 174 related to application of Neut and Alc enzymes were chosen. Cod frames (Sep. 2017) were cut into 175 smaller parts and divided in two batches; minced cod frame (MCF) which was chopped in a blender 176 (Waring blender, model 32BL80, USA) by aid of liquid nitrogen, and heated cod meat (HCM).

177 The HCM fraction was obtained by boiling of cod frame at $95^{\circ} \mathrm{C}$ in a water bath for 20 min with 178 subsequent separation of heated meat from the bones fraction. The samples were mixed with 0.1 $179 \mathrm{M}$ sodium phosphate buffer at $\mathrm{pH} 7.4$ in ratio of 1:1 (w:v) and homogenized for 3 minutes. In 180 individual process, enzymes were added into the sample solution at E/S ratio of 1.5\% (based on 181 sample protein content as determined by Dumas) with subsequent shaking ( $80 \mathrm{rpm})$ in water bath 182 at $50^{\circ} \mathrm{C}$ for $3 \mathrm{~h}$. In the sequential process, sample solution was subjected to Neut for $3 \mathrm{~h}$ and then 183 Alc was added and incubated for the next $3 \mathrm{~h}$. The hydrolysis was terminated by heating the 
184 solution at $95^{\circ} \mathrm{C}$ for $20 \mathrm{~min}$ (Guerard et al., 2002). The hydrolysates were then centrifuged at 6700

$185 \times \mathrm{g}$ for $20 \mathrm{~min}$ (Merck, Beta 1-8, Martin Christ ${ }^{\circledR} \mathrm{GmbH}$, Germany). The supernatant was collected 186 and freeze-dried and grinded into a fine powder, manually, and stored at $4{ }^{\circ} \mathrm{C}$ in dark bottles for

187 further experiments. The process is illustrated in Fig. 1.

\section{SN-TCA index (\%)}

190 The soluble nitrogen content as an indicator of hydrolysis efficiency was calculated by application

191 of trichloroacetic acid (TCA) method as described by Hoyle \& Merritt (1994). Accordingly, 20\%

192 TCA (w/v) solution was prepared and $20 \mathrm{~mL}$ of collected supernatant was added to $20 \mathrm{~mL}$ of TCA 193 (10\% final concentration). The mixture was centrifuged at $7800 \times \mathrm{g}$ for $15 \mathrm{~min}$. The supernatant 194 (soluble protein) was then analyzed for nitrogen content using Dumas instrument $(\mathrm{n}=2)$.

$$
S N-T C A \text { index }=\frac{(\%) \text { SN in } 10 \% \text { TCA supernatant }}{(\%) T N \text { in raw material }} \times 100
$$

196 Where $S N$ is soluble nitrogen, $T N$ is total nitrogen in cod frame meat

198 Nitrogen recovery

199 Nitrogen recovery (NR) in the soluble fraction was calculated using the following formula:

$$
N R(\%)=\frac{N(\%) \text { in FDHP } \times \text { its weight }(g)}{T N(\%) \text { in raw material } \times \text { its weight }(g)} \times 100
$$

201 Where $N$ is nitrogen percentage, $F D H P$ is freeze-dried hydrolysate powder and $T N$ is total nitrogen

202 in cod backbone meat. Nitrogen was determined by the Dumas method as described above. 
205 The yield was calculated as percentage ratio of weight of the initial substrate (cod frame) in gram 206 to the weight of the hydrolysates obtained in gram.

$$
\text { Yield }(\%)=\frac{\text { FDHP weight }(g)}{\text { initial weight of raw material }(g)} \times 100
$$

208 Where FDHP is freeze-dried hydrolysate powder.

\section{FPH Solubility}

211 In order to measure the FPH powder relative solubility, $200 \mathrm{mg}$ of powder were dispersed in 20

$212 \mathrm{~mL}$ of $0.1 \mathrm{M}$ sodium phosphate buffer ( $\mathrm{pH}$ 7.4) and mixed thoroughly (stirring for $10 \mathrm{sec}$.), then

213 mixtures were left at room temperature while shaking $(80 \mathrm{rpm})$ for 30 minutes and finally

214 centrifuged at $7500 \times \mathrm{g}$ for 15 minutes. The protein/peptide content of each supernatant was

215 determined using the Dumas instrument (Brinton et al., 2005). Protein/peptide solubility was

216 calculated as;

$$
\text { Solubility }(\%)=\frac{\text { Protein } / \text { peptide content in supernatant }}{\text { Total protein/peptide content in FPH }} \times 100
$$

\section{Water holding capacity (WHC)}

221 Following the method of Diniz and Martin (1997) with some modification, the WHC was

222 determined by adding $100 \mathrm{mg}$ FPH powder in $1000 \mu \mathrm{l}$ of distilled water followed by mixing with

223 a magnet stirrer. The protein suspension was then centrifuged at $1800 \times \mathrm{g}$ for $20 \mathrm{~min}$ at $22^{\circ} \mathrm{C}$. The

224 supernatant was decanted, and the tube drained at $45^{\circ}$ angle for $10 \mathrm{~min}$. WHC, as $\mathrm{mL}$ of water 225 absorbed per $\mathrm{g}$ of FPH, was calculated based on the difference between initial volumes of distilled 226 water added to the protein sample and the volume retrieved. 


\section{Oil absorption capacity (OAC)}

229 For measuring OAC parameter, an emulsion was prepared by dispersing $100 \mathrm{mg}$ of FPH sample

230 in $1000 \mu \mathrm{l}$ of rapeseed oil for $30 \mathrm{sec}$ following Foh et al., (2010) with slight modification by

231 increasing the protein concentration to $10 \%$ instead of $5 \%$. The resulting emulsion was incubated

232 at room temperature for 30 minutes, and then centrifuged at $13600 \times \mathrm{g}$ for 10 minutes at $25^{\circ} \mathrm{C}$,

233 while Foh et al., (2010) used $2800 \times \mathrm{g}$ for $25 \mathrm{~min}$ without mentioning the temperature. The

234 supernatant decanted and drained at $45^{\circ}$ angle for 15 minutes to determine the volume of absorbed

235 oil. OAC was calculated in the same way as WHC.

236

\section{Bulk Density}

238 Bulk density of freeze-dried cod frame FPH was measured following Foh et al. (2010) with slight

239 modification. Approximately $5 \mathrm{~g}$ of each sample were packed into $50 \mathrm{~mL}$ graduated cylinders by

240 gently tapping on the lab bench 10 times. The volume was recorded and bulk density was reported

241 as $\mathrm{g} / \mathrm{mL}$ of the sample.

\section{Color parameters}

244 The color of the FPH powders was evaluated using the Hunter Lab Miniscan XE colorimeter 245 (Reston, Virginia, USA). The CIE $L^{*} a * b^{*}$ color parameters were used: $L^{*}$; indicating lightness 246 from black (0) to white (100); $a^{*}$; indicating redness from green (- 120/ negative values) to red 247 (+120 / positive values); and $b^{*}$; indicating yellowness going from blue (-120 / negative values)

248 to yellow (+120 / positive values) (Hashemi and Jafarpour, 2016). Whiteness was calculated as:

$$
\text { Whiteness }=100-\sqrt[2]{\left(100-L^{*}\right)^{2}+a^{* 2}+b^{*^{2}}}
$$




\section{Phosphorus and calcium content of peptides and bone fractions}

252 Analysis of calcium and phosphorus in the bone powder was done using ICP-MS (iCAPq, Thermo-

253 Fischer, Germany) in KED mode (helium as cell gas) following digestion of the samples with 254 concentrated nitric acid (SPS Science, France) in a microwave oven (Multiwave 3000).

255 Quantification was done using external calibration with standards made from certified stock 256 solutions of calcium and phosphorus (SPS Science, France) and using rhodium as internal standard

257 (SPS Science, France). A certified reference material DORM-4 (NRCC, Canada) was analyzed 258 together with the samples and the obtained values were in good agreement with the reference 259 values.

\section{Amino acid profile of protein hydrolysates by middle-down proteomics}

262 Freeze-dried protein hydrolysates were prepared using a sodium deoxycholate (SDC) in-solution 263 digestions protocol according to Zhou et al. (2015), without applying the tryptic digestion step. 264 Alkylated peptides were purified using C-18 StageTips (Rappsilber et al., 2007; Yanbao Yu et al., 265 2014), dried down, and re-suspended in $0.1 \%(\mathrm{v} / \mathrm{v})$ trifluoroacetic acid, $2 \%$ acetonitrile (v/v) for 266 analysis. Peptide analysis was performed using an automated LC-ESI-MS/MS, consisting of an

267 EASY-nLC system (Thermo Scientific) on-line coupled to a Q Exactive HF mass spectrometer 268 (Thermo Scientific,) equipped with a Nanospray Flex ion source (Thermo Scientific). Peptides 269 were loaded onto a reverse phase (RP) Acclaim Pepmap Nanotrap column (C18, $100 \AA$, $100 \mu \mathrm{m}$. $270 \times 2 \mathrm{~cm}$, nanoViper fittings (Thermo Scientific)) followed by separation on a RP Acclaim Pepmap

271 RSLC analytical column $(\mathrm{C} 18,100 \AA, 75 \mu \mathrm{m} . \times 50 \mathrm{~cm}$, nanoViper fittings (Thermo Scientific) as 272 described in (García-Moreno et al., 2020). 
273 Proteomics analysis was performed using MaxQuant 1.6.0.16 (Cox and Mann, 2008; Tyanova et

274 al., 2016) using a reference proteome constructed by combining the two available GenBank

275 (Benson et al., 2017; Sayers et al., 2019) assemblies (as of December 10 ${ }^{\text {th }}, 2018$ ) for Gadus morhua

276 (GCA_000231765.1 and GCA_900302565.1) (Star et al., 2013) and removing redundant entries

277 by applying a $90 \%$ identity cutoff. The analysis was performed as unspecific digestion with peptide

278 length from 3 to 65 AAs and applying a false discovery rate of $1 \%$ on both peptide and protein

279 level.

280 The sample-level molar amino acid frequency $f_{A A}^{\text {sample }}$ for each AA was approximated using the

281 peptide-level data output using an MS1 intensity-weighted normalization of the peptide level for

282 each amino acid and summed up over all identified peptides after filtration of reverse hits and

283 potential contaminant peptides according to:

$$
f_{A A}^{\text {sample }}=\sum_{p e p=1}^{n} f_{A A}^{p} * I_{\text {rel }}^{p}
$$

286 Where $f_{A A}^{p}$ is the integral frequency of a given AA in peptide $p$ and $I_{r e l}^{p}$ is the MS1 intensity of 287 peptide $p$ divided by the sum of intensities for all $n$ peptides. To approximate the amount of each 288 AA per $100 \mathrm{~g}$ of samples (i.e. soluble peptides), the sample-level molar AA frequency was 289 multiplied with the MW of the AA (subtracted for water cleaved during peptide bond formation), 290 divided by the weighted average AA MW (110 g/mol) (Kim et al., 2018) and multiplied by 100.

\section{Statistical analysis}


293 The current experiment performed in a completely randomized design test and obtained data were

294 analyzed by one-way ANOVA in SPSS (v. 16.0). Multiple comparison among means was 295 calculated in Tukey as a post hoc test, while setting the confidence level at 95\%.

\section{Results and Discussion}

\section{Characterization of cod frames at different sampling months}

299 Table 1 shows proximate composition of cod frame along with its phosphorus contents as a main 300 mineral component from Mar. 2017 to Mar. 2018 with 3 months sampling intervals. Accordingly, 301 the protein content of cod frame varied from $13 \%$ to $17 \%$. No significant difference $(\mathrm{P}>0.05)$ was 302 observed with the exception of the sample from Sep. $2017(\mathrm{P}<0.05)$, which had the highest protein 303 content. On average, these values are in line with study conducted by Gildberg et al. (2002), who 304 reported the protein content of cod frame as $16 \%$. Generally, it is expected that a higher protein 305 content will be obtained for fish caught during the summer because the higher temperature will 306 cause blooming in late summer of free-floating algae, specifically cyanobacteria (Groetsch et al., 307 2016). Hence, more food sources are available for nourishing the fish during the summer season.

308 However, in the current study, higher protein content in sample Sep. 2017 might be related to 309 inefficiency of fillet trimming machine, which could result in a higher proportion of meat 310 remaining on the bone in the batch received in this sampling month. The support for this claim is 311 that the ash and phosphorous content do not correlate with the protein content in sample Sep. 2017;

312 otherwise, these values should be higher than those recorded for sample Sep. 2017. The low protein 313 content of cod frame from Mar. 2017 to Jun. 2017 is in line with the study reported by Ingolfsdottir 314 et al. (1998), who attributed the lowest protein content in North Atlantic cod muscle to the period 315 of spawning of cod during March to May. 
316 In terms of phosphorus (P) content, the sample from Sep. 2017 contained the lowest amount of 317 2.2\%, while the highest amount was determined in Mar. 2018 followed by Dec. 2017 (4.4\% and $3183.7 \%$, respectively) $(\mathrm{P}<0.05)$. This trend coincides well with the lower content of other fractions 319 such as protein and lipid. This can result in higher percentage of $\mathrm{P}$ in calculated proximate 320 composition of cod frame. However, the $\mathrm{P}$ content of cod frame in our study is not in agreement 321 with those reported by Toppe et al. (2007) and Malde et al. (2010) as $113 \mathrm{~g} / \mathrm{kg}$ and $180 \mathrm{~g} / \mathrm{kg}$, 322 respectively. The difference in reported $\mathrm{P}$ values is mainly due to the reason that in the current 323 study, the P content (Table 1) was analyzed on the ash fraction and calculated based on the whole 324 cod frame. In contrast, by measuring the P content based on the dried bone powder (Table 8) its 325 value was $170 \mathrm{~g} / \mathrm{kg}$, which is in line with that reported by Malde et al. (2010). Cod is classified as 326 a lean fish (with lipid content of lower that 2\%) (Zeng et al., 2010), and the lipid content of samples 327 in our study recorded a low value of around 1\% during different sampling months. However, the 328 slight changes in lipid content of cod frame in our study showed no correlation with the typical 329 lipid content of fish muscle during spawning and feeding seasons. The lipid content of the cod 330 frame (0.98\% to $1.13 \%)$ was higher than those obtained by Gildberg et al. (2002) and Zeng et al. 331 (2010), who reported the lipid content of cod backbone and cod flesh as $0.3 \%$ and $0.8 \%$, 332 respectively. Furthermore, Ingolfsdottir et al. (1998) reported that the values for the fat content of 333 North Atlantic cod muscle varied from less than $0.15 \%$ in the autumn to higher than $0.35 \%$ in the 334 late spring. On the other hand, according to Toppe et al. (2007), the lipid content of cod backbone 335 was reported as $2.3 \%$, which is significantly higher than those recorded in our study and the study 336 conducted by Ingolfsdottir et al. (1998). Obviously, the lipid content of cod frame in our study is 337 surprisingly high as it stems from residual cod meat on the frame. Most of the frame must be bone, 338 so if the lipid content in the frame is higher than what was reported by others in pure cod muscle, 
339 then it means that the meat left on the cod bone investigated in our study contains more lipid than

340 the cod filet itself.

341 In case of dry matter, the highest content was determined in the samples from Dec. 2017 and Mar.

3422018 (about 22\%) and the lowest amount in the sample of Jun. $2017(19.4 \%, \mathrm{P}<0.05)$. As

343 aforementioned, the different content of dry matters may be related to the exact ratio between meat

344 and bone and not necessarily be directly related to seasonal variation. Therefore, the fluctuations

345 in proximate composition of cod frame in our study cannot be attributed to the feasting (March-

346 June) and fasting (September-December) seasons. In other words, the highest protein and lipid

347 content and lowest dry matter and phosphorus content were recorded for fish caught in Sep. 2017

348 (fasting season), whereas, protein and lipid content showed a declining trend during feasting

349 season. However, for proper interpretation of seasonal variation in proximate composition of cod

350 frame, it would be necessary to consider real seasonality versus differences in filleting efficiency,

351 which may in fact be influenced by seasonal changes in cod meat texture and functional properties

352 (Malcolm Love, 1979). However, to unveil the true influence of seasonality on the proximate

353 composition, the amino acids and fatty acid profile of samples during different seasons should be

354 analyzed, which will be discussed in following sections. Consequently, based on the type of 355 application, i.e. targeting mainly protein or phosphorus, cod frame can be selected from different 356 seasons as a valuable source for valorization process which creates new high value ingredients 357 preferably without generating new wastes.

\section{Amino acid profile of cod frame in different seasons}

360 Amino acids are considered as precursors for synthesis of a broad range of biologically important 361 substances including nucleotides, peptide hormones, and neurotransmitters. Total amino acid 
content of cod frame is presented in Table 2, and is divided into two sections: essential amino acids

363 (EAA) and non-essential amino acids (NEAA). A significant seasonal variation is observed among

364 the AAs with different patterns. For instance, there is a sinusoidal pattern in the content of Thr,

365 Val, Ser, Gly, Ala, Asp and Glu with an increase in the first half of year (Mar. to Sep. 2017)

366 followed by a decline up to the end of year (Dec. 2017) and again a rise in Mar. 2018. Whereas,

367 for Met, Phe, His, Tyr and C-C a slight fluctuation was recorded during different sampling months.

368 On the other hand, Ile and Arg presented a sharp increase during spring (Mar.-Jun. 2017) followed

369 by a sharp decline during the rest of the sampling months and nearly the same pattern was observed

370 for Leu. The highest content of total AAs $(155.83 \mathrm{mg} / \mathrm{g})$ was found in the sample from Sep. 2017 ,

371 while the lowest content of $97.93 \mathrm{mg} / \mathrm{g}$ was recorded for sample Mar. 2017. This corresponds well

372 with the protein content of cod frame determined by proximate composition analysis. With the

373 exception of the cod frame sample from Mar. 2017, which showed nearly equal amount of EAAs

374 and NEAAs, the content of EAAs was remarkably lower than the NEAA content. The EAA

375 occurring in the highest amount was Val with its highest values in samples Jun. and Sep. 2017

376 (15.02 and $15.42 \mathrm{mg} / \mathrm{g}$, respectively) while the EAA which occurred in lowest amounts (2.16-

$3773.32 \mathrm{mg} / \mathrm{g}$ ) was His. In case of NEAAs, Glu had the highest abundance (14-22.12 mg/g), while the

378 C-C content was lower than $1.0 \mathrm{mg} / \mathrm{g}$ in all samples.

379 Toppe et al. (2007) reported that AAs profile of cod bone is rich in Gly $>$ Glu $>$ Arg $>$ Pro $>$ Asn, and 380 poor in $\operatorname{Trp}<\mathrm{His}<\mathrm{Tyr}<\mathrm{Ile}<\mathrm{Phe}$, which was relatively in agreement with our results. Thus, cod 381 frame in our study contained large amounts of Glu $>$ Gly $>$ Val followed by nearly same amounts of 382 Ala, Asp, Pro, Leu and Lys, with their peak values in sample Sep. 2017. The possible explanation 383 for the difference in the content of some AAs in these two studies might be due to the nature of 384 analyzed sample. Toppe et al. (2007) used a farmed codfish, while in our study the frame of wild 
385 codfish was examined. Furthermore, it is noteworthy that regarding the Glu and Asp content in 386 our study, they are determined as sum components of Glu+Gln and Asp+Asn due to conversion 387 during hydrolysis prior to analysis. Higher amounts of Gly, Ala and Pro compared to other NEAA 388 content of cod frame, especially in sample Sep. 2017, could indicate high amounts of collagenous 389 peptides in the raw material (de Paz-Lugo et al., 2018).

\section{$391 \quad$ Fatty acid (FA) profile}

392 It is generally accepted that highly unsaturated n-3 fatty acids (n-3 HUFA) or long-chain n-3 393 polyunsaturated fatty acids (LC n-3 PUFA), particularly 20:5 n-3 (eicosapentaenoic acid [EPA]) 394 and 22:6 n-3 (docosahexaenoic acid [DHA]) positively affect human health such as early 395 development, and the prevention of some diseases (Vonder Haar et al., 2016). According to the 396 FA profile of cod frame (Table 3), the most abundant FAs was determined as DHA (23.0-24.9\%), 397 followed by palmitic acid (C16:0, 13.5-17.5\%), EPA (11.5-15.6\%) and oleic acid (C18:1n9, 11.1398 11.8\%). FAs with lower frequency included eicosenoic acid, stearic acid isomer of oleic acid, 399 lignoceric, palmitoleic acid, dihomo-gamma-linolenic acid and cetoleic acid, while the rest were $400 \leq 1.0 \%$ at all sampling points.

401 These results do not coincide with Toppe et al. (2007), where the most abundant FAs of farmed 402 cod backbone was reported to be oleic acid followed by palmitic acid, DHA and EPA. In another 403 study conducted on farmed Atlantic cod fillet by Zeng et al. (2010), the authors reported DHA as 404 the most abundant FA (31.0\%), and a total of $48,8 \%$ of n-3 PUFAs in the total lipid of cod muscle.

405 The same trend but lower content was observed in our study, most possibly due to the differences 406 in the raw material used, i.e, cod muscle in Zeng et al. (2010) study, versus cod frame with 407 remaining meat in our study. Furthermore, all analyzed samples contained higher amounts of n-3 
PUFAs (ranging from 37.66 to $40.64 \%$ ) than n-6 PUFAs (ranging from 2.5 to $2.8 \%$ ) (Table 3 ).

409 Toppe et al. (2007) reported these values as $12.6 \%$ and $1.9 \%$ for n-3 PUFAs and n-6 PUFAs,

410 respectively. In our study, apart from a slight increase in n-3 PUFAs, starting from Mar. 2017 and

411 reaching to its highest value in Dec. 2017, no profound seasonal variation was observed on PUFAs

412 profile.

413 Referring to the proximate composition of cod frame with emphasis on protein and phosphorus

414 content and also with respect to high levels of EAAs and NEAAs in different months, cod frame

415 could be considered as a valuable source for further valorization experiments in order to recover

416 bioactive compounds such as peptides, calcium and phosphorous without producing more waste.

417 In accordance with the aforementioned statement, this study evaluated the release of potentially

418 bioactive peptides by enzymatic hydrolysis and recovery of calcium and phosphorous from the 419 remaining bones as added-value components.

420

421 Valorization of cod frames

422 SN-TCA index

423 For a given substrate and enzyme at a given $\mathrm{pH}$, the comparison of different hydrolysates is based

424 on the degree of hydrolysis (DH) as it was measured in terms of SN-TCA in our study. DH depends

425 on the experimental variables such as the type of enzyme, substrate and applied conditions (e.g.

426 time, temperature, $\mathrm{pH}, \mathrm{E} / \mathrm{S}$ ratio,) (Williams, 2004). As shown in Table 4, application of Alc and

427 Neut, either separately or sequentially on two types of fish substrate, resulted in 30-40\% SN-TCA

428 index. Alc was more efficient compared to Neut on both MCF or HCM, whereas, Neut and Alc

429 did not show any substrate preference, as the resulting SN-TCA index was not significantly 
430 different between these two substrates ( $p>0.05$ ). However, sequential application of Neut\&Alc to

431 the MCF caused significantly higher SN-TCA index compared to HCM $(p<0.05)$.

432 In our study, the main experimental variables were the enzyme and substrate types, which affected

433 the dependent variables differently. In addition, applied enzymes were calculated based on the 434 same concentration $(1.5 \% \mathrm{w} / \mathrm{w})$. Thus, they cannot be directly compared as Alc has a specified 435 activity three times higher than Neut (2.4 AU/g vs. $0.8 \mathrm{AU} / \mathrm{g})$, i.e, to make this comparison, three 436 times more Neut should have been added. Therefore, we cannot claim that application of Alc on 437 the cod backbone meat was more efficient compared to Neut treatment. Nevertheless, the higher 438 efficiency of Alc compared to Neut was reported by Gildberg et al. (2002). These authors 439 stipulated that the lower efficiency of Neut could be related to higher susceptibility to the inhibitory 440 activity of protease inhibitors found in cod meat. Therefore, it is expected that application of 441 preheating treatment on the substrate before enzymatic hydrolysis, could enhance the efficiency 442 of Neu treatment. However, this is not in agreement with results of our study as Neut still showed 443 low efficiency in case of $\mathrm{HCM}$ (including pretreatment at $95^{\circ} \mathrm{C}$ for $20 \mathrm{~min}$ ) (further investigation 444 needed). On the other hand, Liaset et al. (2000) reported higher DH in case of Neut (23\%) 445 compared to pepsin (15\%) and Alc (20\%) on salmon and cod frame, but these authors applied Neut 446 enzyme with $\mathrm{E} / \mathrm{S}$ ratio of $30 \mathrm{AU} / \mathrm{kg}$ protein versus $3.6 \mathrm{AU} / \mathrm{kg}$ protein in our study.

447 When running the enzymatic hydrolysis process, it is also important to figure out the amount of 448 recovered protein and nitrogen after enzymatic hydrolysis. It is noticeable that despite the higher 449 yield obtained with the MCF treatment (Table 4), its protein content was significantly lower than $450 \mathrm{HCM}(\mathrm{p}<0.05)$ most probably due to the difference in substrate composition as MCF contains fish

451 bones while HCM is only comprised of fish meat. However, in terms of nitrogen recovery 452 percentage (NR\%), individual application of Alc and Neut resulted in significantly higher NR\% 
453 in MCF compared to $\mathrm{HCM}(\mathrm{P}<0.05)$, whereas subjecting MCF and $\mathrm{HCM}$ to sequential application

454 of Netu\&Alc caused no significant difference in NR\% (P>0.05). In terms of yield percentage the

455 same trend as for NR\% was observed, i.e highest yield was obtained by application of Alc either

456 individually or along with Neut on both MCF and HCM substrate $(\mathrm{P}<0.05)$, mainly due to its

457 higher applied AU/g compared to Neut in our study.

458

459 Color parameters of FPH powder

460 Color parameters of recovered hydrolysate powder from cod frame is presented in Table 5. In 461 terms of substrate type, peptide powder from enzymatic hydrolysis of HCM resulted in higher $L^{*}$

462 value, but lower $a^{*}$ and $b^{*}$ values compared to MCF substrate, which resulted in whiter recovered

463 FPH powder from $\mathrm{HCM}(\mathrm{P}<0.05)$. Among all examined treatments, Alc showed highest ability to

464 result in lighter and consequently whiter powder from HCM substrate. By comparing the MCF 465 data, even though, the Neut treatments caused higher $L^{*}$ values, the whiteness of the obtained 466 powder was significantly lower compared to the rest of treatments $(\mathrm{P}<0.05)$. This is mainly due to 467 its higher redness and yellowness values, which are negatively correlated to the whiteness index.

468 In a study conducted by Šližyte et al. (2009) on cod backbone, color parameters of recovered FPH 469 powder were recorded as $L^{*}=87.8, a^{*}=-0.7$, and $b^{*}=17.5$. In comparison, the trends in color 470 values in our study is generally in line with values reported by Šližyte et al. (2009) as nearly the

471 same yellowness, higher lightness and lower redness was recorded for recovered FPH from cod

472 frame. This will positively affect its customer popularity and market acceptability. Apart from the

473 broad specificity of Alc and Neut, the differences in color values can be attributed to the difference

474 in cleavage site of enzymes in peptide chain, which could contribute differently to the color of the

475 obtained peptide powder. Furthermore, apart from the enzyme type, several other parameters such 
476 as differences in color measuring instruments, E/S ratio and types, enzyme concentration etc.,

477 could influence the color of obtained FPH powder.

479 FPH Solubility and water holding capacity (WHC)

480 The solubility of the FPH powders at a certain concentration $(1 \% \mathrm{w} / \mathrm{v})$ are shown in Table 6 , and 481 ranged from $93 \%$ to $100 \%$ which is in agreement with other studies (Klompong, Benjakul, 482 Kantachote, \& Shahidi, 2007; Nalinanon, Benjakul, Kishimura, \& Shahidi, 2011; Pacheco-Aguilar 483 et al., 2008; Taheri et al., 2013). In comparison, administration of Alc on both MCF and HCM and 484 also Neut\&Alc treatment on HCM resulted in significantly higher solubility $(\mathrm{P}<0.05)$ than the 485 other treatments, while lowest solubility was determined for the hydrolysate from Neut treatment 486 on MCF $(\mathrm{P}<0.05)$, followed by Neut\&Alc on MCF and Neut on HCM.

487 Protein solubility to a large extent depends on $\mathrm{pH}$ values, showing its lowest solubility close to the 488 isoelectric point (pI) (Chobert et al., 1988; Linder et al., 1996). The pH influences the charge on 489 the weakly acidic and basic side-chain groups with subsequent effects on the protein solubility 490 (Gbogouri et al., 2004) which is proportional to the square of the net charge on the protein (Shaw 491 et al., 2001). Improved solubility of the hydrolyzed protein compared to its original form can be 492 attributed to the degradation of the proteins leading to increased repulsive interactions between 493 peptides and a subsequent increase in hydrogen bonding with water molecules (Souissi et al., 494 2007). The hydrolysis degrades proteins to peptides, which are generally more soluble. However, 495 the increased solubility of the peptides is largely caused by the fact that peptides hydrophobic 496 domains is lower compared to the intact protein molecule.

497 Due to the high solubility of the hydrolysates, the WHC of obtained FPH powders was close to 498 zero. In contrast to our results, Taheri et al. (2012) reported high WHC $(5.1 \mathrm{~mL} / \mathrm{g})$ for fish 
499 hydrolysate powder recovered from rainbow trout viscera using Alc, which possibly is related to

500 the higher DH in their study compared to ours. According to Kristinsson and Rasco (2000), the

501 increased concentration of polar groups such as $\mathrm{COOH}$ and $\mathrm{NH}_{2}$ that is caused by extensive

502 enzymatic hydrolysis has a substantial positive effect on the amount of adsorbed water. Apart from

503 different substrate types, the differences in reported studies can possibly be explained by the

504 number and ratio of polar and nonpolar groups (hydrophilic and hydrophobic amino acids), and

505 the amino acid composition of the FPH recovered with each enzyme. According to Trevino et al.

506 (2007), Asp, Glu, and Ser contribute more favorably to protein solubility than the other hydrophilic

507 amino acids especially at high net charge. In our study, the inability of obtained FPH to imbibe

508 water molecules can be possibly attributed to the dominant portion of released hydrophilic amino

509 acid residues with low net charge, which results in weak hydrogen bonds that could not retain it

510 against the gravitational force in the protein matrix. In addition, the common practice in protease

511 hydrolysis in aqueous solution is to collect the supernatant after enzymatic process by

512 centrifugation, which cause a major loss of hydrophobic amino acids that goes to the precipitated

513 sediment. Consequently, peptides are more prone to hydration compared to undenatured protein.

514 However, depending on the type of FPH application, both solubility and WHC are considered as

515 important FPH functionality parameters as these can influence other functionalities such as

516 emulsification and foaming properties.

518 Oil absorption capacity $(O A C)$ and bulk density (BD)

519 The highest OAC was obtained for hydrolysates produced by Alc treatment of both MCF and 520 HCM substrates $(\mathrm{P}<0.05)$, while the lowest values were related to the individual application of

521 Neut and sequential application of Neut\&Alc on either MCF or HCM ( $\mathrm{P}>0.05)$ (Table 6). It is 
522 believed that OAC is mainly dependent on physical entrapment of oil, which is directly related to

523 the hydrophobic surface of hydrolyzed proteins (Kristinson \& Roscoe, 2000), protein mass density,

524 and their amino acid composition.

525 BD represents the physical property of a product, which influence the packaging requirements of 526 a product. Therefore, to obtain higher BD, higher degree of hydrolysis is required, which in turn

527 lower the molecular size of resulting peptides (may also drastically change the biological, physical

528 and chemical properties of the hydrolysate) and consequently a finer powder with less porosity

529 would be obtained.

530 In terms of $\mathrm{BD}$ values, there was a significant difference $(\mathrm{P}<0.05)$ among the various samples

531 studied (Table 6). HCM hydrolyzed sequentially with Neut\&Alc showed significantly higher BD

532 of $0.40 \mathrm{~g} / \mathrm{mL}$ followed by MCF sample $(0.35 \mathrm{~g} / \mathrm{mL})(\mathrm{P}<0.05)$. However, HCM hydrolyzed with

533 Neut and Alc separately, showed the lowest values of $0.19 \mathrm{~g} / \mathrm{mL}$ and $0.25 \mathrm{~g} / \mathrm{mL}$, compared to MCF

534 samples with BD values of 0.31 and $0.28 \mathrm{~g} / \mathrm{mL}$, respectively $(\mathrm{P}<0.05)$. Considering the fact that

535 MCF samples contained bone, this can likely explain the difference as these treatments may get

536 different collagen derived peptides along with a likely higher content of minerals, which contribute

537 to a higher density of the sample as a whole. Foh et al. (2010) studied the functionality of FPH

538 from hydrolyzed Tilapia (Oreochromis niloticus) and reported that BD of resulting peptide powder

539 from Neut heat treated fish mince was significantly lower compared to Alc treatment which is in 540 accordance with the current study.

541

542 Amino acid profile of FPH by middle down proteomics

543 The AA profile of cod frame protein hydrolysates ( $\mathrm{g} / 100 \mathrm{~g}$ of soluble peptide) is presented in Table

544 7. It should be noted that the AA profile is an approximation by means of peptide-level MS1 
545 intensity weighing, and that peptide MS1 intensities are not in all cases proportional to peptide 546 abundance due to variability in peptide physiochemical properties. Furthermore, the AA profile

547 presented here only takes into account AAs found in (potentially bioactive) peptides (3-65 AAs)

548 released by enzymatic hydrolysis and does not take into account free AAs nor larger protein 549 fragments. Consequently, it is challenging to compare directly to other studies, where it has been 550 common to analyze either free AA or total AA profiles, where both free AAs and total AAs from 551 non-hydrolyzed proteins are included. Although analysis of total AA content provides valuable 552 insight into e.g. nutritional value of a substrate, our approach provides a novel and alternative way 553 of characterizing protein hydrolysates in terms of peptide AA composition.

554 As seen in Table 7, apart from the sequential application of Neut\&Alc on HCM, all other 555 treatments resulted in release of peptides with higher content of EAAs from both MCF and HCM 556 substrates compared to the original Sep. 2017 sample. The most abundant AAs in the identified 557 peptides were Glu, Leu, Asp, Pro and Phe, in all treatments. The highest content of the EAAs were 558 Leu, Phe and Val and was found in peptides released from the cod frame by the sequential 559 application of Neut\&Alc on both MCF and HCM, while application of Neut was responsible for 560 significantly higher content of Thr, Lys and Gln. In case of NEAAs, the highest content of Gly 561 and Pro was found in peptides released by Alc, while hydrolysis by Neut resulted in release of 562 peptides richest in Ala and Glu for both MCF and HCM. Interestingly, the content of Lys, Gln, 563 Glu, and Cys was over two-fold higher in hydrolysates only treated with Neut compared to other

564 treatments. This trend was also seen to a lower extent for Thr and Asn. This could indicate that 565 treatment with Alc may be responsible for release of these AAs in free form to a much higher 566 extent or those peptides rich in these AAs are to a larger extent hydrophobic and hence not found 567 in the FPH. Furthermore, the peptides obtained using sequential hydrolysis with Neut\&Alc had a 
568 significantly lower content of His and Arg, indicating that this treatment may result in increased 569 release of free positively charged AAs. The increased release of charged AAs in free form, could 570 contribute to an increased antioxidant activity of the peptides obtained with sequential Neut\&Alc

571 treatment, as these AAs are reported to be positive contributors to peptide antioxidant activity 572 compared to other AAs (Udenigwe and Aluko, 2011). The lower content of Cys in the sequential 573 hydrolysate peptides may impair antioxidant activity; however, as free Cys is known to have 574 significant antioxidant activity by itself due to the high redox potential of the thiol group, the total 575 antioxidant potential of the sequential hydrolysate may be significant. This aspect is currently 576 under investigation.

577 As the obtained hydrolysate powder in the current study was prepared from the Sep. 2017 sample, 578 it is reasonable to compare the AAs profile of these two samples (Table 7). Accordingly, the most 579 abundant EAAs in the intact proteins from the cod frame were Val, Lys, Leu and Ile, whereas, the 580 most abundant AA in released peptides by different enzymatic treatments were Leu, Phe and Val. 581 The relatively low content of His in the hydrolysates corresponded well with the analysis of the 582 cod frame from Sep. 2017 sample. Nevertheless, the hydrolysate peptides had, in general, a higher 583 content of EAAs compared to the total AA analysis of Sep. 2017 sample (Table 7), indicating that 584 the majority of EAAs are found in peptides and not free AA form. In terms of NEAAs, total AA 585 analysis revealed, by far, the highest abundance of Glu and Gly (14.2 and $11.2 \mathrm{~g} / 100 \mathrm{~g})$. The high 586 content of Glu was also seen in the hydrolysate peptides (11.9 g/100g soluble peptide on average), 587 while the Gly content in the peptides was somewhat more moderate $(5.31 \mathrm{~g} / 100 \mathrm{~g}$ soluble peptide 588 on average), indicating that Gly is released to a high extent as free AA in the hydrolysates or found 589 in insoluble peptides. By direct comparison, total AA analysis of Sep. 2017 sample appear to have 590 a general enrichment of Gly and Ala while the peptides from hydrolysis are slightly enriched in 
591 Pro, Asp, and Tyr. Moreover, Cys (in the disulfide form (C-C)) was not detected in the cod frame

592 total AA analysis and only found in very low amount in the hydrolysate $(0.11 \mathrm{~g} / 100 \mathrm{~g}$ soluble

593 peptide on average). Hyp was not included in the proteomics analysis of hydrolysates, while Asn

594 was not included in the AA analysis of the cod frame.

595 In this study, the most abundant EAA in hydrolysate peptides was Leu $(11.7 \mathrm{~g} / 100 \mathrm{~g}$ soluble peptide

596 on average), while the EAA with lowest abundance was His $(1.14 \mathrm{~g} / 100 \mathrm{~g}$ soluble peptides on

597 average). This corresponds well with the findings of Tan et al. (2018) who studied the nutritional

598 properties of enzymatic hydrolysates of cod bone proteins. According to these authors, the most

599 abundant AAs were as Glu, Gly, Lys, Arg, Ala, Thr and Leu, which is largely in agreement with

600 the cod frame AA profile. In our study, in case of NEAAs, highest abundance was observed for

601 Glu with $11.9 \mathrm{~g} / 100 \mathrm{~g}$, followed by Asp and Pro. According to Cao et al. (2008), Lys and Arg are

602 connected with the healthy function of FPH and in our study, these AAs were found in highest

603 abundances (4.27 to $7.85 \mathrm{~g} / 100 \mathrm{~g}$ soluble peptide) in Neut-driven FPH, which is good indication

604 of health benefits of prepared FPH from cod frame using Neut hydrolysis.

605 Sabeena Farvin et al. (2016) stated that the predominant amino acids in industrially prepared cod

606 hydrolysate were Glu (14.5\%), Gly (13.4\%), Lys (8.4\%) and Ala (7.7\%) of the total amino acids

607 content. However, as it was mentioned earlier, the AA profile in our study is not directly 608 comparable with others as we here only determine the AA composition in FPH peptides.

610 Calcium and phosphorus content

611 Calcium and phosphorus contents in either bone powders from MCF and HCM treatments or its

612 residual in FPH powder are presented in Table 8. On top of that, the amount of protein content in

613 dried bone powder of cod frame was measured to be in the range of $30-43 \%$ (data not shown). In 
614 case of phosphorus and calcium content, bone-Neut\&Alc sample on MCF resulted in significantly

615 higher concentrations ( 330 and $583 \mathrm{~g} / \mathrm{kg}$ of phosphorus and calcium, respectively), compared to

616 those from the other treatments $(\mathrm{p}<0.05)$. Statistically, no significant difference was observed

617 between control sample (bone-boiling) with those obtained by individual application of Neut and

618 Alc on MCF ( $\mathrm{P}>0.05)$. This result is an indication of the efficiency of sequential application of

619 Neut\&Alc on recovery of minerals from leftover bone fractions after enzymatic hydrolysis, while

620 containing substantial amount of protein too. Interestingly, there was no significant difference in

621 phosphorus content of FPH powders $(\mathrm{P}>0.05)$. On the contrary, the calcium content of FPH

622 powder from HCM was significantly higher than that from MCF treatments, indicating loss of a

623 minor part of calcium (around $0.1 \%$ ) in obtained bone powder after boiling of fish frame compared

624 with bone powder obtained after enzymatic treatment. Thus, application of enzymatic hydrolysis

625 on cod frame before separating meat and bone fraction can results in significantly higher value of

626 calcium and phosphorus in obtained bone powder $(\mathrm{P}<0.05)$, while its protein content was lower

627 compared to dried bone powder obtained by drying at $50{ }^{\circ} \mathrm{C}$ from the frame without enzymatic

628 hydrolysis. However, further experiments are needed to clarify the effect of type of treatments on

629 the bioavailability of obtained minerals and protein.

630 Fish bone consists of both organic and inorganic (mineral) parts. Kim and Jung (2006) reported

631 the inorganic mineral portion as $69.5 \%$ on dry basis, which was mainly composed of $59.7 \%$ of

632 calcium $(\mathrm{Ca})$ and $35.8 \%$ of phosphorus $(\mathrm{P})$ with the $\mathrm{Ca} / \mathrm{P}$ mole ratio of 1.67 . In the current study,

633 the $\mathrm{Ca} / \mathrm{P}$ mole ratio was between 1.6 to 1.7 , which is close to the desired ratio for human bones,

634 and in agreement with the results reported by other researchers (Kim et al., 2018; Logesh et al.,

635 2012; Nemati et al., 2017). According to Toppe et al. (2007), P and Ca content of cod bone are

636113 and $190 \mathrm{~g} / \mathrm{kg}$ of lipid free dry matter, respectively. In another study, conducted by Malde et 
637 al. (2010), these minerals were reported as 180 and $248 \mathrm{~g} / \mathrm{kg}$ of boiled cod bone, which is in nearly 638 comparable with P and Ca values recorded in our study as 170 and $297 \mathrm{~g} / \mathrm{kg}$ of boiled cod bone, 639 respectively. However, the mineral content of bone-Neut\&Alc sample was as twice and triple as 640 those reported by Malde et al. (2010) and Toppe et al. (2007), respectively. The findings of the

641 present study indicated that cod frame is rich in calcium, phosphorus and protein, which can be

642 considered as a potential source in fortification of food products for human consumption.

643

\section{Conclusions}

645 In this study, the proximate composition, phosphorous content, amino acid and fatty acid profiles

646 of cod frame from five different catchment periods were evaluated. Apart from some amino acids,

647 no profound variation was observed in proximate composition of cod frame among different 648 catchment periods. Therefore, it can be considered as a steady and valuable side-stream source 649 based on its high content of calcium, phosphorus, protein, and low fat content (dominantlyn-3 fatty 650 acids, namely, EPA and DHA), as well as potentially bioactive peptides by enzymatic hydrolysis.

651 Further studies are needed to evaluate the functional properties of the obtained peptides and the 652 bioavailability of calcium and phosphorous of the resultant bone powder.

\section{Acknowledgment}

655 Authors sincerely appreciate Mrs. Riuyinosa Igbinovia, for her assistance regarding the seasonality 656 variation analyses and Mrs. Annette Landin for the ICPMS analyses. We are also grateful of the 657 Espersen Company from Lithuania for collaboration and providing the cod frame samples from 658 different seasons. The study was financed by the JPA Espersen fund. 
661 Benson, D.A., Cavanaugh, M., Clark, K., Karsch-mizrachi, I., Ostell, J., Pruitt, K.D., Sayers, E.W., 2017.

662 Dennis A. Benson, Mark Cavanaugh, Karen Clark, Ilene Karsch-Mizrachi, James Ostell, Kim D. Pruitt and

663 Eric W. Sayers *. Nucleic Acids Res. 46, 41-47. https://doi.org/10.1093/nar/gkx1094

Bligh, E.G., Dyer, W.J., 1959. A rapid method of total lipid extractin and purification. Can. J. Biochem.

Brinton, P.H.M.P., Schertz, F.M., Crockett, W.G., Merkel, P.P., 2005. A Modification of the Dumas Method, and the Application of the Kjeldahl Method to the Determination of Nitrogen in Nitronaphthalenes. J. Ind. Eng. Chem. 13, 636-639. https://doi.org/10.1021/ie50139a026

Cao, W., Zhang, C., Hong, P., Ji, H., 2008. Response surface methodology for autolysis parameters optimization of shrimp head and amino acids released during autolysis. Food Chem. 109, 176-183. https://doi.org/10.1016/J.FOODCHEM.2007.11.080

Chalamaiah, M., Dinesh kumar, B., Hemalatha, R., Jyothirmayi, T., 2012. Fish protein hydrolysates: Proximate composition, amino acid composition, antioxidant activities and applications: A review. Food Chem. 135, 3020-3038. https://doi.org/10.1016/J.FOODCHEM.2012.06.100

Chobert, J.M., Bertrand-Harb, C., Nicolas, M.G., 1988. Solubility and emulsifying properties of caseins and whey proteins modified enzymatically by trypsin. J. Agric. Food Chem. 36, 883-892. https://doi.org/10.1021/jf00083a002

Cox, J., Mann, M., 2008. MaxQuant enables high peptide identification rates, individualized p.p.b.-range mass accuracies and proteome-wide protein quantification. Nat. Biotechnol. 26, 1367-72. https://doi.org/10.1038/nbt.1511

De Paz-Lugo, P., Lupiáñez, J.A., Meléndez-Hevia, E., 2018. High glycine concentration increases collagen synthesis by articular chondrocytes in vitro: acute glycine deficiency could be an important cause of osteoarthritis. Amino Acids 50, 1357-1365. https://doi.org/10.1007/s00726-018-2611-x

Diniz, F.M., Martin, A.M., 1997. Effects of the Extent of Enzymatic Hydrolysis on Functional Properties of Shark Protein Hydrolysate. LWT - Food Sci. Technol. 30, 266-272. https://doi.org/10.1006/FSTL.1996.0184

FAO, 2018. FAO Fisheries statistics 2016. FAO, Rome.

Foh, M.B.K., Amadou, I., Foh, B.M., Kamara, M.T., Xia, W., 2010. Functionality and antioxidant properties of tilapia (Oreochromis niloticus) as influenced by the degree of hydrolysis. Int. J. Mol. Sci. 11, 1851-1869. https://doi.org/10.3390/ijms11041851

García-Moreno, P.J., Gregersen, S., Nedamani, E.R., Olsen, T.H., Marcatili, P., Overgaard, M.T., Andersen, M.L, Hansen, E.B., Jacobsen, C. (In Press). Identification of emulsifier potato peptides by bioinformatics: application to omega-3 delivery emulsions and release from potato industry side streams. Scientific Reports. https://doi: 10.1038/s41598-019-57229-6

Gbogouri, G.A., Linder, M., Fanni, J., Parmenter, M., 2004. C : Food Chemistry and Toxicology Influence of Hydrolysis Degree. J. Food Sci. 69g, 615-622. https://doi.org/10.1111/j.1365-2621.2004.tb09909.x 
Ghelichi, S., Sørensen, A.-D.M., García-Moreno, P.J., Hajfathalian, M., Jacobsen, C., 2017. Physical and 
Malcolm Love, R., 1979. The post-mortem ph of cod and haddock muscle and its seasonal variation. J. Sci. Food Agric. 30, 433-438. https://doi.org/10.1002/jsfa.2740300414

Malde, M.K., Bügel, S., Kristensen, M., Malde, K., Graff, I.E., Pedersen, J.I., 2010. Calcium from salmon and cod bone is well absorbed in young healthy men: A double-blinded randomised crossover design. Nutr. Metab. 7, 1-9. https://doi.org/10.1186/1743-7075-7-61

Melton, J.L., 1995. Perspectives: How many women have osteoporosis now? J. Bones Miner. Res. 10, 175177.

Murillo, E., Rao, K.S., Durant, A.A., 2014. The lipid content and fatty acid composition of four eastern central Pacific native fish species. J. Food Compos. Anal. 33, 1-5. https://doi.org/10.1016/j.jfca.2013.08.007

Nemati, M., Huda, N., Ariffin, F., 2017. Development of calcium supplement from fish bone wastes of yellowfin tuna (Thunnus albacares) and characterization of nutritional quality. Int. Food Res. J. 24, 24192426.

Oliveira, V.D.M., Bezerra, R.D.S., Assis, C.R.D., 2015. Fish pepsin: basic characteristics, extraction, determination and biotechnological applications. Nat. Resour. 4, 6-14. https://doi.org/10.6008/spc2237$\underline{9290.2014 .001 .0001}$

Rappsilber, J., Mann, M., Ishihama, Y., 2007. Protocol for micro-purification, enrichment, pre-fractionation and storage of peptides for proteomics using StageTips. Nat. Protoc. 2, 1896-1906. https://doi.org/10.1038/nprot.2007.261

Robinson, P.K., 2015. Enzymes: principles and biotechnological applications. Essays Biochem. 59, 1-41. https://doi.org/10.1042/BSE0590001

Sabeena Farvin, K.H., Andersen, L.L., Otte, J., Nielsen, H.H., Jessen, F., Jacobsen, C., 2016. Antioxidant activity of cod (Gadus morhua) protein hydrolysates: Fractionation and characterisation of peptide fractions. Food Chem. 204, 409-419. https://doi.org/10.1016/J.FOODCHEM.2016.02.145

Sayers, E.W., Agarwala, R., Bolton, E.E., Brister, J.R., Canese, K., Clark, K., Connor, R., Fiorini, N., Funk, K., Hefferon, T., Holmes, J.B., Kim, S., Kimchi, A., Kitts, P.A., Lathrop, S., Lu, Z., Madden, T.L., Marchler-Bauer, A., Phan, L., Schneider, V.A., Schoch, C.L., Pruitt, K.D., Ostell, J., 2019. Database resources of the National Center for Biotechnology Information. Nucleic Acids Res. 47, D23-D28. https://doi.org/10.1093/nar/gky1069

Shaw, K.L., Grimsley, G.R., Yakovlev, G.I., Makarov, A.A., Pace, C.N., 2001. The effect of net charge on the solubility, activity, and stability of ribonuclease Sa. Protein Sci. 10, 1206-1215. https://doi.org/10.1110/ps.440101

Šližyte, R., Mozuraityte, R., Martínez-Alvarez, O., Falch, E., Fouchereau-Peron, M., Rustad, T., 2009. Functional, bioactive and antioxidative properties of hydrolysates obtained from cod (Gadus morhua) backbones. Process Biochem. 44, 668-677. https://doi.org/10.1016/j.procbio.2009.02.010

Soetan, K.O., Olaiya, C.O., Oyewole, O.E., 2010. The importance of mineral elements for humans, domestic animals and plants - A review. African J. Food Sci. 4, 200-222. 
Souissi, N., Bougatef, A., Triki-Ellouz, Y., Nasri, M., 2007. Biochemical and functional properties of sardinella (Sardinetta aurita) by-product hydrolysates. Food Technol. Biotechnol. 45, 187-194.

Star, B., Nederbragt, A.J., Jentoft, S., Grimholt, U., Gregers, T.F., Rounge, T.B., Paulsen, J., Solbakken, M.H., 2013. Europe PMC Funders Group The genome sequence of Atlantic cod reveals a unique immune system 477, 207-210. https://doi.org/10.1038/nature10342.The

Tan, X., Qi, L., Fan, F., Guo, Z., Wang, Z., Song, W., Du, M., 2018. Analysis of volatile compounds and nutritional properties of enzymatic hydrolysate of protein from cod bone. Food Chem. 264, 350-357. https://doi.org/10.1016/J.FOODCHEM.2018.05.034

Terzioğlu, P., Öğ̈̈t, H., Kalemtaş, A., 2018. Natural calcium phosphates from fish bones and their potential biomedical applications. Mater. Sci. Eng. C 91, 899-911. https://doi.org/10.1016/J.MSEC.2018.06.010

Toppe, J., Albrektsen, S., Hope, B., Aksnes, A., 2007. Chemical composition, mineral content and amino acid and lipid profiles in bones from various fish species. Comp. Biochem. Physiol. Part B Biochem. Mol. Biol. 146, 395-401. https://doi.org/10.1016/J.CBPB.2006.11.020

Trevino, S.R., Scholtz, J.M., Pace, C.N., 2007. Amino Acid Contribution to Protein Solubility: Asp, Glu, and Ser Contribute more Favorably than the other Hydrophilic Amino Acids in RNase Sa. J. Mol. Biol. 366, 449-460. https://doi.org/10.1016/j.jmb.2006.10.026

Tyanova, S., Temu, T., Cox, J., 2016. The MaxQuant computational platform for mass spectrometry-based shotgun proteomics. Nat. Protoc. 11, 2301-2319. https://doi.org/10.1038/nprot.2016.136

Udenigwe, C.C., Aluko, R.E., 2011. Chemometric analysis of the amino acid requirements of antioxidant food protein Hydrolysates. Int. J. Mol. Sci. 12, 3148-3161. https://doi.org/10.3390/ijms12053148

Vonder Haar, C., Peterson, T.C., Martens, K.M., Hoane, M.R., 2016. Vitamins and nutrients as primary treatments in experimental brain injury: Clinical implications for nutraceutical therapies. Brain Res. https://doi.org/10.1016/j.brainres.2015.12.030

Williams, A.P., 2004. Enzymic hydrolysis of food proteins, Food Chemistry. https://doi.org/10.1016/0308$\underline{8146(87) 90169-5}$

Yanbao Yu, Pieper, R., Smith, M., 2014. A spinnable and automatable StageTip for high throughput peptide desalting and proteomics. Protoc. Exch. 1.

Zeng, D., Mai, K., Ai, Q., Milley, J.E., Lall, S.P., 2010. Lipid and fatty acid compositions of cod (Gadus morhua), haddock (Melanogrammus aeglefinus) and halibut (Hippoglossus hippoglossus). J. Ocean Univ. China 9, 381-388. https://doi.org/10.1007/s11802-010-1763-4

Zhou, N.A., Kjeldal, H., Gough, H.L., Nielsen, J.L., 2015. Identification of Putative Genes Involved in Bisphenol A Degradation Using Differential Protein Abundance Analysis of Sphingobium sp. BiD32. Environ. Sci. Technol. 49, 12231-12241. https://doi.org/10.1021/acs.est.5b02987 